\title{
Bubble departure diameter determination for pool boiling on surface with microchannels
}

\author{
Robert Kaniowski ${ }^{1}$, Robert Pastuszko ${ }^{1, *}$, Joanna Kowalczyk ${ }^{1}$ and Lukasz Nowakowski ${ }^{1}$ \\ ${ }^{1}$ Kielce University of Technology, Faculty of Mechatronics and Mechanical Engineering, al. 1000-lecia Państwa Polskiego 7, \\ PL-25-314 Kielce, Poland
}

\begin{abstract}
The paper presents visualization investigations into pool boiling heat transfer for open microchannel surfaces. The experiments were carried out with saturated water, ethanol, FC-72 and Novec649 at atmospheric pressure. Parallel microchannels fabricated by machining copper sample were about 0.2 to $0.5 \mathrm{~mm}$ wide and 0.2 to $0.5 \mathrm{~mm}$ deep. The diameter of departing bubble was calculated for the microchannel surface on the basis of buoyancy force and surface tension force balance. The visualization carried out was aimed at determining the diameters of the departing bubbles at various heat fluxes for four working fluids.
\end{abstract}

\section{Introduction}

Modern technology determines the development of devices that are dimensionally smaller and have an increasing demand for energy. The leading problem of modern technology is the reception of high heat flux. This is an extremely significant issue from an economic, as well as technological point of view, and in the context of environmental protection. Devices that generate highvalue heat fluxes include e.g. digital systems, nuclear reactors, combustion engines, gas turbines. The achievement of high values of heat transfer coefficients reduces the dimensions and consumption of materials needed for the construction of heat exchangers, and also reduces energy consumption during technological processes. Miniaturization and increased power of electronic circuits have given rise to the need for more efficient cooling units. A tendency has been observed in the design of heat exchangers to reduce their volume and weight. A passive cooling method comprises heat transfer between the refrigerant and the heat-emitting surface at boiling. The boiling heat transfer is very intensive, but in the case of technically smooth surfaces it does not provide sufficient dissipation of high heat fluxes. Therefore, there is a need to develop methods to increase the heat transfer surface. These include the use of extended heating microsurfaces, e.g. by creating parallel incisions in the form of grooves. The progress of experimental and theoretical research has led to the development of a variety of surfaces. A series of studies related to active heat exchange for FC-72 during the flow of liquid through channels has been described in [13].

The diameter of a departing vapor bubble is one of the basic parameters used in the description of pool boiling, hence the issue has been analyzed by various authors. The available literature provides many formulas for the bubble departure diameter, but most of them relate to pool boiling on flat, smooth surfaces. In relation to boiling on surfaces such as tunnel-pore or subsurface tunnels created in the fins or minifins [4-6], the authors usually present a complicated methodology of calculations.

Ramaswamy et al. [7] have specified 6 forces, the combination of which has enabled the calculation of the departing bubble diameter: (1) unsteady growth force, (2) buoyancy force, (3) surface tension force, (4) lift force, (5) bubble inertia force and (6) liquid inertia force. The authors have assumed that in the case of inertia driven growth, the velocity of the bubble front is constant, hence there was no inertia force.

Pastuszko [8] proposed calculating the departing bubble diameter for the microfins with wire mesh surface on the basis of buoyancy force and surface tension balance referred to the pore diameter. Cooke and Kandlikar [9] used the high speed video to show that the bubbles attached to each side of the microchannel. They assumed that the bubbles were spherical and there was liquid in the microchannel below the bubble. Walunj and Sathyabhama [10] used force balance similar to given by Ramaswamy et al. [7]. Due to the use of microchannels with different geometries, the authors gave their own dependence on surface tension force, including channel base and top width as well as channel depth. Their bubble diameter model predicted the experimental data with mean absolute error of abort 5.6\%.

\section{Investigated enhanced surfaces}

The specimens with test surfaces were made of copper and had parallel grooves with a constant pitch, made

Corresponding author: tmprp@tu.kielce.pl 
a)

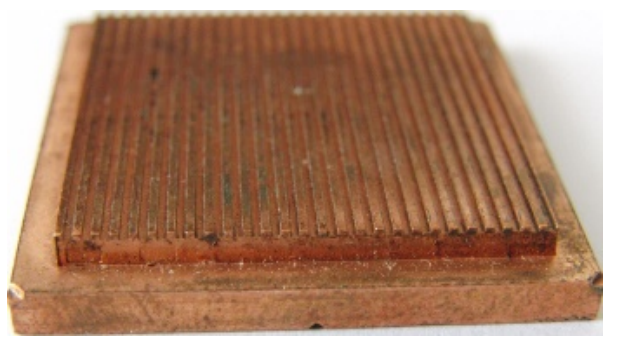

b)

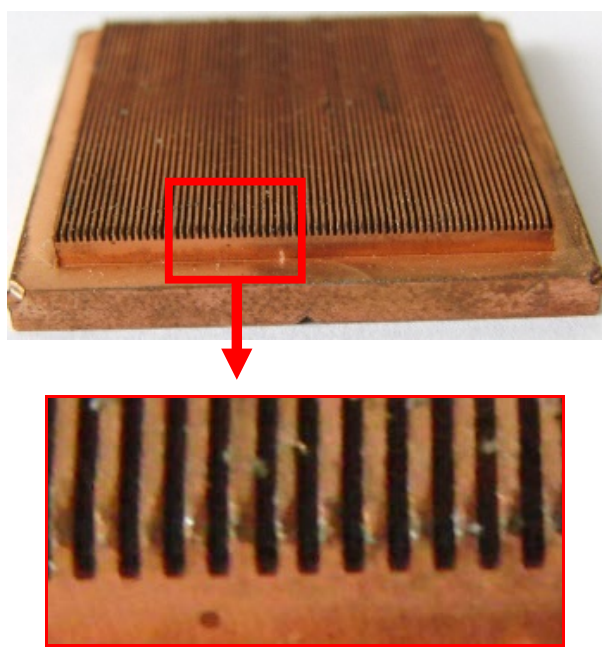

c)

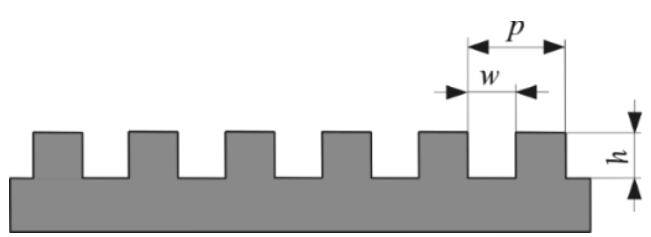

Fig. 1. View of specimen (a) MC 0.5-0.5-1.0 (b) MC 0.2-0.50.4 with magnification, (c) MC dimension symbols.

with an end mill of 0.2 to $0.5 \mathrm{~mm}$ in diameter (CNC machining process), Fig. $1 \mathrm{a}, \mathrm{b}$. The test section consists of a 32 × $32 \mathrm{~mm}^{2}$ square copper specimen with a $27 \times 27 \mathrm{~mm}^{2}$ boiling region. Figure $1 \mathrm{~b}$ shows a magnification of the microchannels and Fig. 1c dimension symbols.

The static contact angle was measured using Biolin Scientific's Attension Theta Tensiometer. The test consisted of placing a drop of liquid of approximately 4 $\mu l$ on the surface of a metal sample. An image was recorded with a fast monochrome camera, starting from the moment the drop touched the surface of the disc for about 10 seconds. After the completion of research, an analysis of the images was performed. Results obtained after approximately 0.2 seconds from the moment of application of drops onto the surface of the tested sample were selected. An average of the achieved results was calculated. Tests were performed using distilled water, ethanol, FC-72 and Novec-649. Droplets were applied onto a copper sample.

Figure 2 shows the contact angle between a copper specimen and water. The smallest contact angle, therefore the best surface moistening results, were achieved with ethanol, while the worst wetting results were observed with water and amounted to $99.1^{\circ}$, as in
Fig. 3. This means that water does not moisten copper, as the achieved wetting angle is greater than $90^{\circ}$.

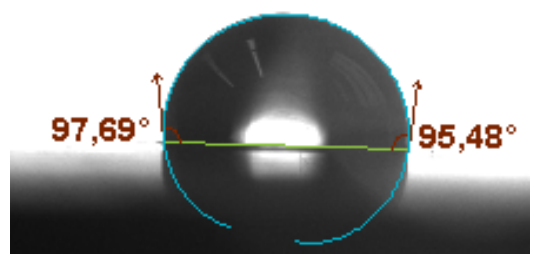

Fig. 2. Contact angle between a copper sample and water.

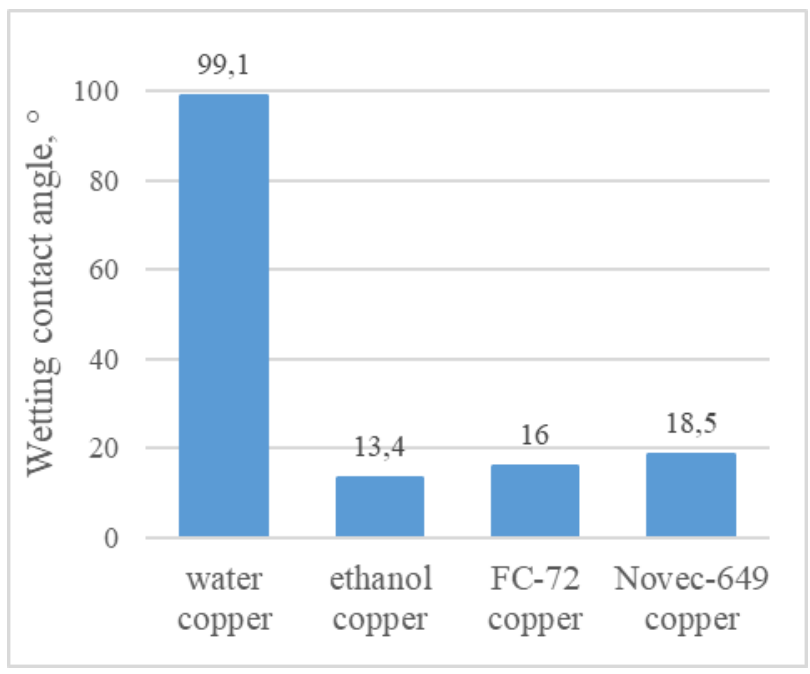

Fig. 3. Contact angle between a copper sample and working fluid.

Figure 4 shows the view of the MC 0.2-0.5-0.4 specimen and its roughness profile, Fig. 5, which was determined using a Talysurf CCI - Lite non-contact $3 D$ Profiler, a measurement system for optical, non-contact analysis of geometric structures of surfaces [11]. Table 1 compiles the surface codes and specifications with mean roughness on the top of microfins and the bottom of selected microchannels.

Table 1. MC surface codes and specifications.

\begin{tabular}{|c|c|c|c|c|c|}
\hline Sample code & $\begin{array}{c}w \\
\mathrm{~mm}\end{array}$ & $\begin{array}{c}h \\
\mathrm{~mm}\end{array}$ & $\begin{array}{c}p \\
\mathrm{~mm}\end{array}$ & $\begin{array}{c}R a_{t} \\
\mu \mathrm{m}\end{array}$ & $\begin{array}{c}R a_{b t} \\
\mu \mathrm{m}\end{array}$ \\
\hline MC-0.2-0.5-0.4 & 0.2 & 0.5 & 0.4 & 24 & 30 \\
\hline MC-0.2-0.4-0.4 & 0.2 & 0.4 & 0.4 & 14 & 25 \\
\hline MC-0.2-0.3-0.4 & 0.2 & 0.3 & 0.4 & 20 & 14 \\
\hline MC-0.2-0.2-0.4 & 0.2 & 0.2 & 0.4 & 30 & 30 \\
\hline MC-0.3-0.5-0.6 & 0.3 & 0.5 & 0.6 & 14 & 25 \\
\hline MC-0.3-0.4-0.6 & 0.3 & 0.4 & 0.6 & 18 & 18 \\
\hline MC-0.3-0.3-0.6 & 0.3 & 0.3 & 0.6 & 20 & 12 \\
\hline MC-0.3-0.2-0.6 & 0.3 & 0.2 & 0.6 & 18 & 12 \\
\hline MC-0.4-0.5-0.8 & 0.4 & 0.5 & 0.8 & 25 & 21 \\
\hline MC-0.4-0.4-0.8 & 0.4 & 0.4 & 0.8 & 31 & 14 \\
\hline MC-0.4-0.3-0.8 & 0.4 & 0.3 & 0.8 & 25 & 15 \\
\hline MC-0.4-0.2-0.8 & 0.4 & 0.2 & 0.8 & 22 & 12 \\
\hline MC-0.5-0.5-1.0 & 0.5 & 0.5 & 0.8 & 31 & 41 \\
\hline MC-0.5-0.4-1.0 & 0.5 & 0.4 & 0.8 & 36 & 28 \\
\hline MC-0.5-0.3-1.0 & 0.5 & 0.3 & 0.8 & 22 & 15 \\
\hline MC-0.5-0.2-1.0 & 0.5 & 0.2 & 0.8 & 20 & 13 \\
\hline & & & & & \\
\hline
\end{tabular}


a)

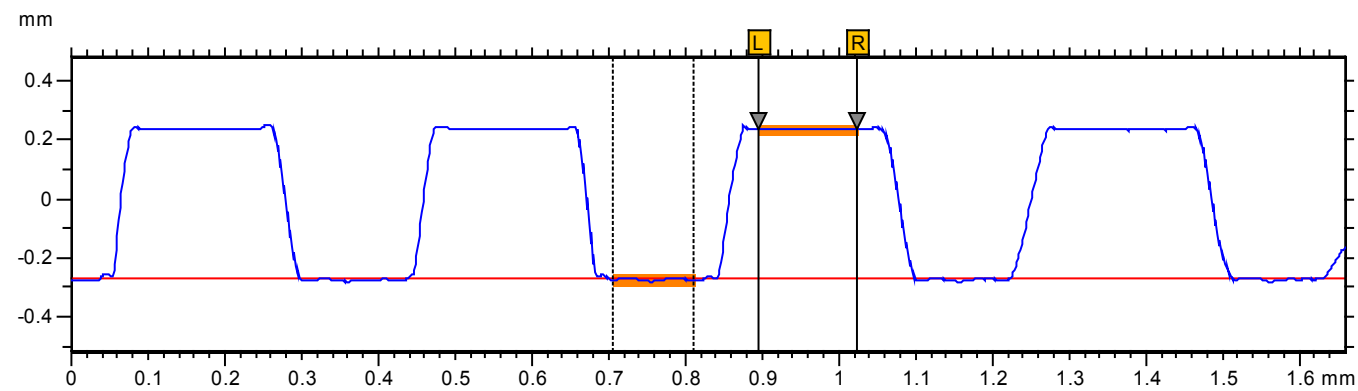

b)

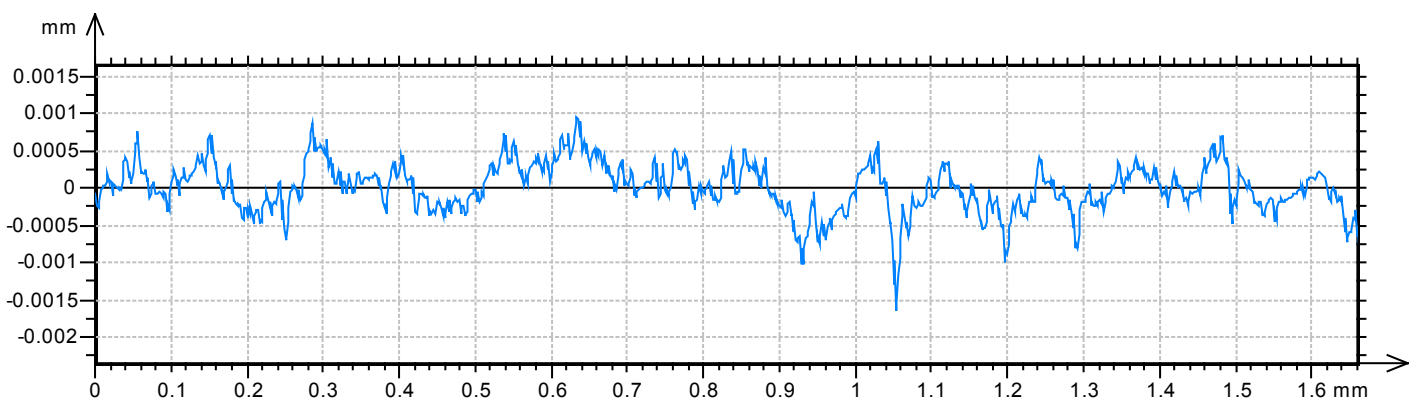

c)

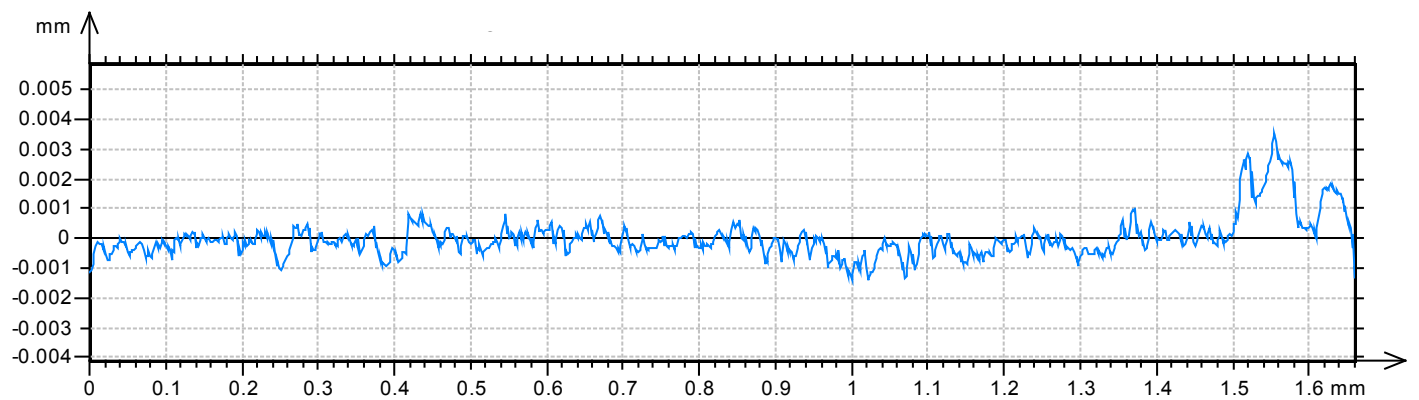

Fig. 4. MC 0.2-0.5-0.4 (a) microchannel outline, (b) microchannel top, (c) microchannel bottom.

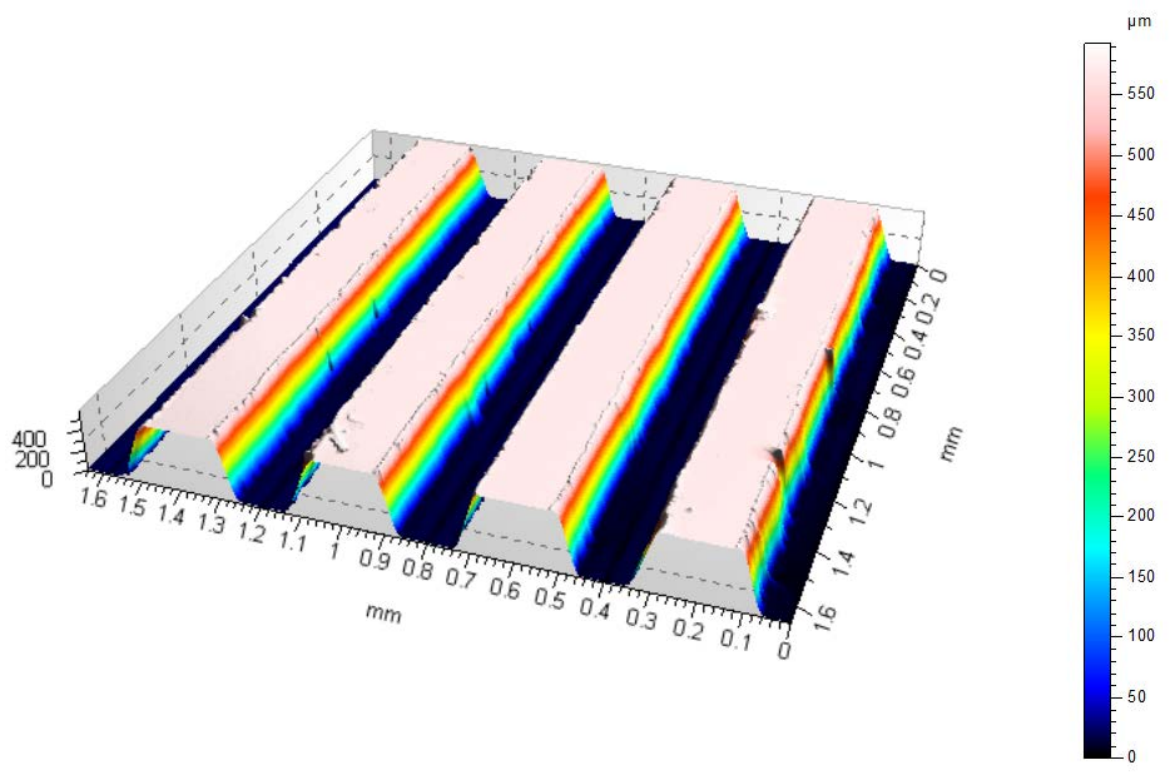

Fig. 5. Profile of the surface roughness of the microchannel, MC 0.2-0.5-0.4. 


\section{Experimental setup}

The diagram of the measuring unit is presented in Fig. 6 [8]. The following modules constituted the experimental setup:

A. main module (items $1-6$ );

B. vapor cooling and condensate recovery (item 7);

C. temperature measurement and data acquisition module (items 8-10);

D. power supply module (item 11);

E. visualization module (digital camera/digital video camera, item 12).

The visualization images were obtained using a high speed digital monochrome camera MV-D1024-160-CL (Photonfocus) with resolution of 500x250 pixels at 458 fps as well as with photo camera Casio EX-FH20.

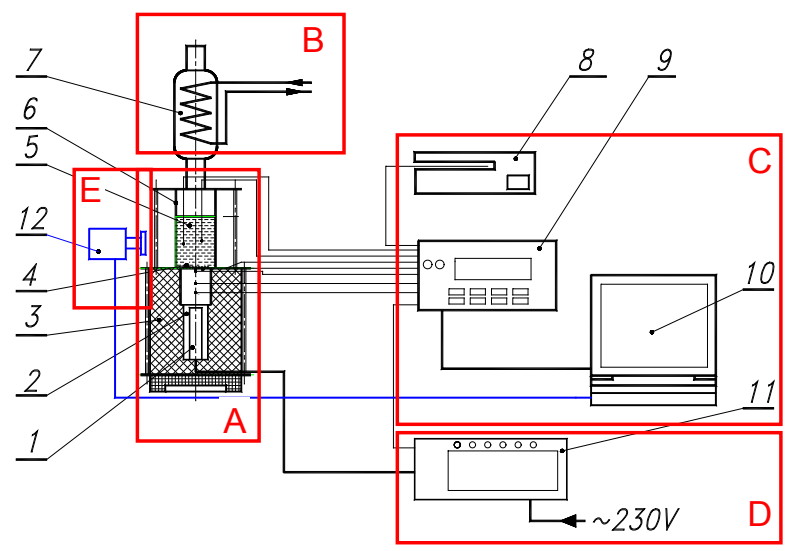

Fig. 6. Schematic diagram of the test system: 1 - cartridge heater; 2 - copper bar; 3 - insulation; 4 - investigated structure; 5 - boiling liquid; 6 - glass vessel; 7 - condenser; 8 - dry-well calibrator; 9 - data logger; 10 - PC; 11 - power regulator; 12 - digital camera/video camera.

\section{Results}

\subsection{Boiling visualization}

Figure 7 illustrates boiling of Novec-649 on the surface MC-0.3-0.2-0.6 at atmospheric pressure. Most bubbles are generated in the microchannel space, but we can also observe bubbles in contact with the upper surface of the microfins, as well as bubbles departing at the tops of the microfins.

The largest bubbles, with a diameter corresponding to $2-3$ pitches of microchannels, were formed as a result of coalescing.

\subsection{Bubble departure diameter determination}

The authors proposed the calculation of the diameter of departing bubbles for the analyzed surface on the basis of buoyancy force and surface tension force balance. This is a rough estimate that does not take into account the inertia force during bubble growth. Buoyancy force can be calculated from:

$$
F_{b u}=\frac{\pi d_{b}^{3}}{6} g\left(\rho_{l}-\rho_{v}\right)
$$

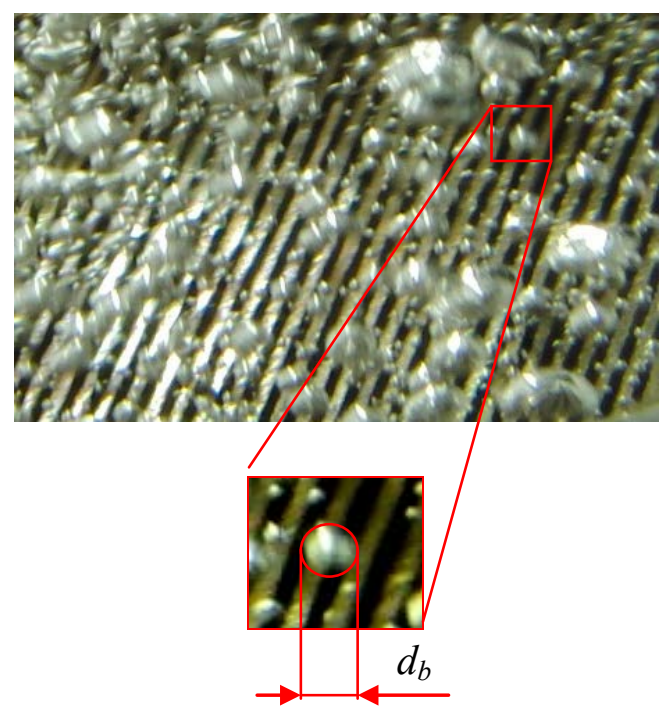

Fig. 7. Visualization observations of pool boiling of Novec-649 on the microchannel surface MC-0.3-0.2-0.6, $q=2.8 \mathrm{~kW} / \mathrm{m}^{2}$.

Surface tension force acting on the bubble at departing is determined by assuming that, just before detachment, the bubble base (neck) is in contact with the upper edges of microfins along the length equal to the width of the microchannel (Fig. 8). The length of the contact line is therefore $L_{c}=2 w$, and dependence on the surface tension force is defined as:

$$
F_{s}=\sigma L_{c} \sin \Theta
$$

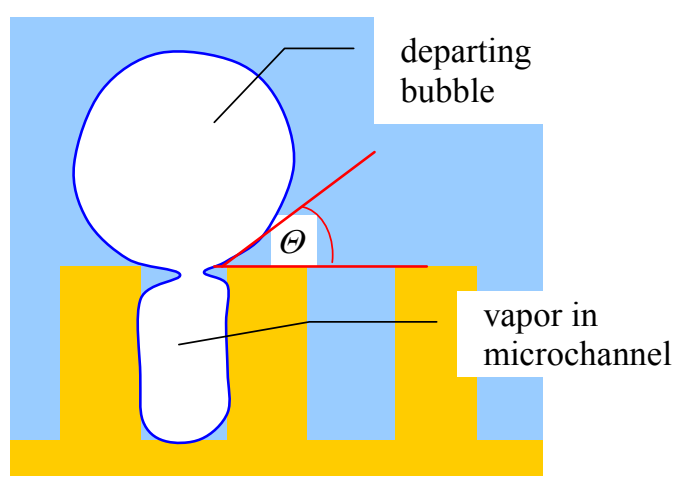

Fig. 8. Bubble departing at microfins tops.

The contact angle $\theta$ is shown in Fig 8. Table 2 also shows for comparison the capillary length values, where this parameter is defined as:

$$
L_{\text {cap }}=\sqrt{\frac{\sigma}{g\left(\rho_{l}-\rho_{v}\right)}}
$$

For the analyzed microchannel widths, the calculated diameter of departing bubbles is smaller than the capillary length. According [9] the surface between liquid and vapor has a constant radius if the channel width is less than the capillary length. 
Table 2. Selected parameters and calculated values of the departing bubbles diameters for four working fluids.

\begin{tabular}{|c|c|c|c|c|c|}
\hline \multicolumn{2}{|c|}{$\begin{array}{l}\text { Parameters } \\
\text { at } p=101.3 \mathrm{kPa}\end{array}$} & Water & Ethanol & FC-72 & $\begin{array}{l}\text { Novec- } \\
649\end{array}$ \\
\hline \multicolumn{2}{|c|}{$T_{\text {sat }},{ }^{0} \mathrm{C}$} & 100 & 78.3 & 56.4 & 49.0 \\
\hline \multicolumn{2}{|c|}{$\rho_{l}, \mathrm{~kg} / \mathrm{m}^{3}$} & 959 & 757 & 1602 & 1513 \\
\hline \multicolumn{2}{|c|}{$\rho_{v}, \mathrm{~kg} / \mathrm{m}^{3}$} & 0.597 & 1.43 & 13.24 & 13.42 \\
\hline \multicolumn{2}{|c|}{$i_{l v}, \mathrm{~kJ} / \mathrm{kg}$} & 2251 & 963 & 94.9 & 88.0 \\
\hline \multicolumn{2}{|c|}{$\lambda_{l}, \mathrm{~W} / \mathrm{mK}$} & 0.68 & 0.169 & 0.055 & 0.059 \\
\hline \multicolumn{2}{|c|}{$\sigma_{l,}, \mathrm{~N} / \mathrm{m}$} & 0.0589 & 0.0177 & 0.0081 & 0.0108 \\
\hline \multirow{3}{*}{$\begin{array}{l}d_{b,} \\
\mathrm{~mm}\end{array}$} & $w=0.2 \mathrm{~mm}$ & 1.68 & 0.75 & 0.48 & 0.56 \\
\hline & $w=0.3 \mathrm{~mm}$ & 1.92 & 0.86 & 0.55 & 0.64 \\
\hline & $w=0.4 \mathrm{~mm}$ & 2.11 & 0.95 & 0.6 & 0.71 \\
\hline \multicolumn{2}{|c|}{$L_{c a p}, \mathrm{~mm}$} & 2.5 & 1.55 & 0.72 & 0.86 \\
\hline
\end{tabular}

Assuming that $F_{b u}=F_{s}$, on the basis of formulas (1) and (2) we can establish the bubble departing diameter as:

$$
d_{b}=\left(\frac{12 \sigma w \sin \Theta}{\pi g\left(\rho_{l}-\rho_{v}\right)}\right)^{1 / 3}
$$

It should be noted that the contact angles determined by the authors were defined in static conditions, but with the increase of bubble size, their values are subject to change. The diameters of departing bubbles for contact angle values provided in Fig. 1 have been specified in Table 2.

Figure 9 shows influence of heat flux on departing bubble diameter for four working fluids. At small heat fluxes $\left(q<25 \mathrm{~kW} / \mathrm{m}^{2}\right.$ for water and ethanol and $q<7$ $\mathrm{kW} / \mathrm{m}^{2}$ for FC-72 and Novec-649), averaged diameters are approximate in value to the predicted ones in equation 4. At higher heat fluxes there are significant discrepancies between experimental measurements and computational values, which can be explained by the tendency to coalesce.

It was assumed a modified suction-evaporation boiling mode in microchannels (Fig. 10). The whole process of bubble formation consists of a waiting period, a growth period and a liquid intake period. A vapor bubble forms in the corner at the microchannel base and grows as a result of liquid evaporation in the microchannel space. The regions of vapor outflow and bubble generation are determined. The inside of the microchannel is filled with vapor, except for a thin film of liquid at the walls and in menisci.

\section{Conclusions}

The experimental studies and theoretical calculations discussed in this paper led to the following conclusions:

- Determined experimentally static contact angles were used to determine the diameter of bubbles depart from the surface of micro-channels. These angles were then a)

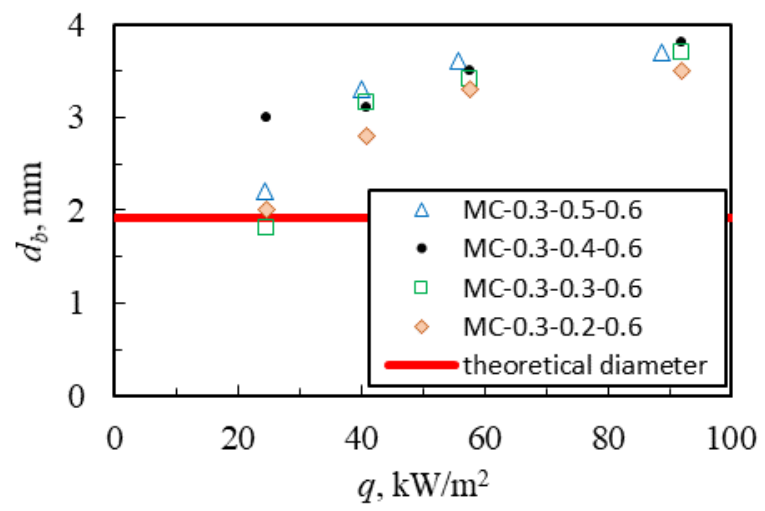

b)

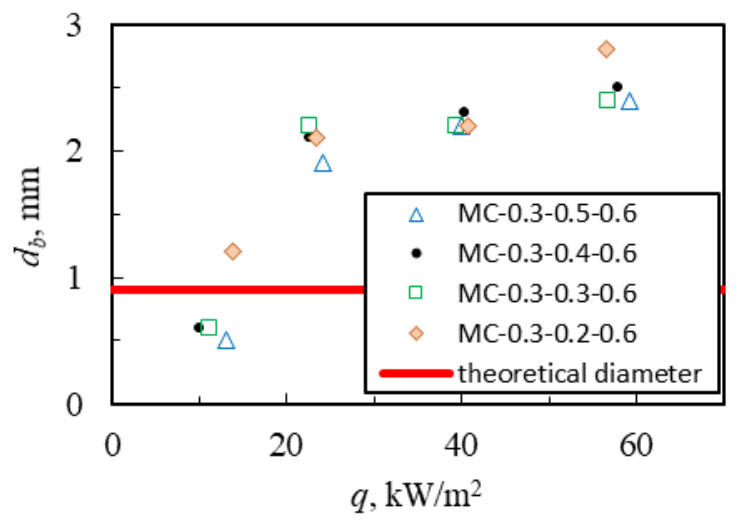

c)

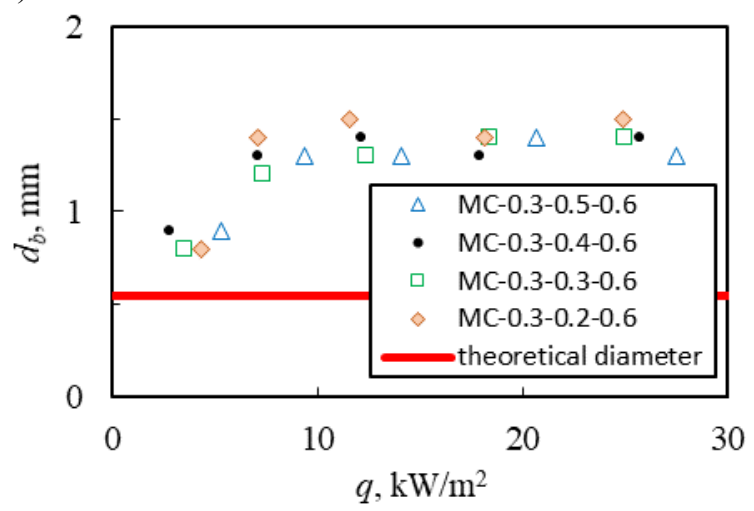

d)

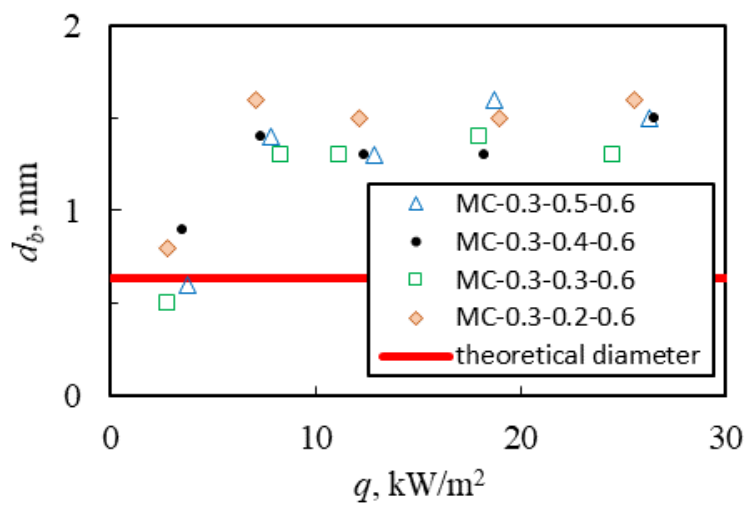

Fig. 9. Averaged departure bubble diameters for (a) water, (b)ethanol, (c) FC-72, (d) Novec-649, theoretical value $d_{b}$ was calculated from eq. 4 . 


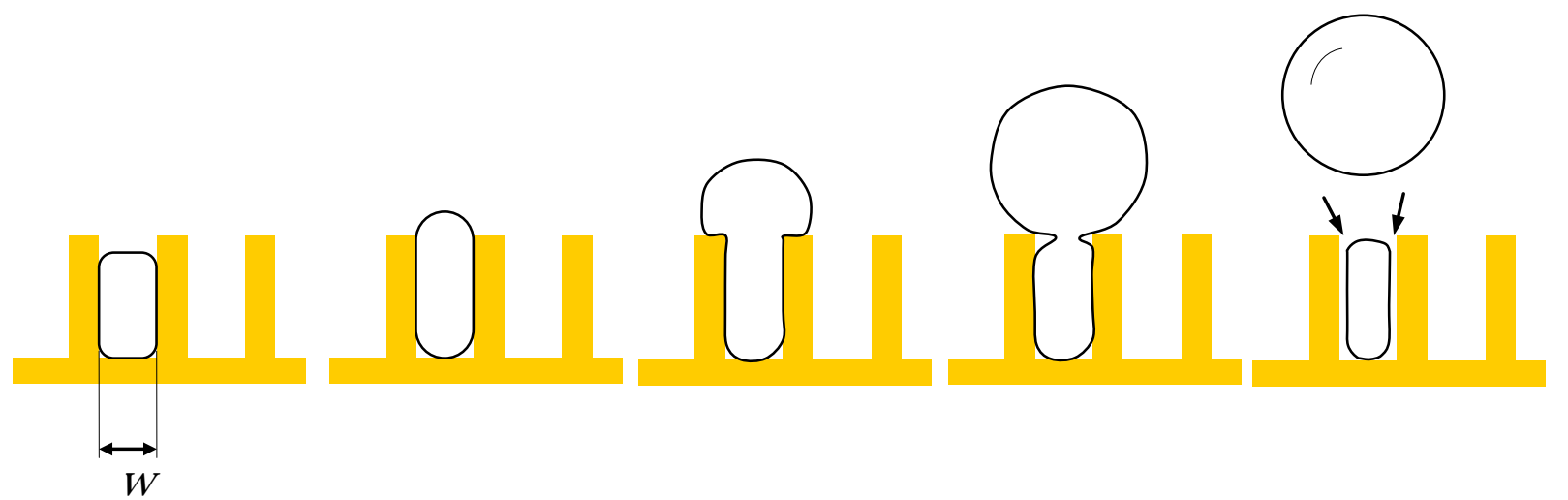

Fig. 10. Bubble growing and departing cycle in microchannel.

related to the cycle of formation of vapor in microchannels, with the assumption that the microchannel was completely filled with vapor.

- In the case of small superheats between the heating surface and the liquid, vapor bubbles take spherical shapes and do not coalesce.

- Bubble diameters became stable after reaching the limit of about $40 \mathrm{~kW} / \mathrm{m}^{2}$ for water, $20 \mathrm{~kW} / \mathrm{m}^{2}$ for ethanol and $7 \mathrm{~kW} / \mathrm{m}^{2}$ for FC-72 and Novec-649.

- The contact angle for water is 5.5- 7.4 times greater than the contact angle for ethanol, FC-72 and Novec.

- Theoretically determined bubble departing diameters are consistent with experimental data for low superheats and heat fluxes. Even three times larger diameters determined experimentally at higher heat fluxes compared to computational values can be explained by changes in the contact angle at boiling temperatures and the tendency of bubbles to coalesce.

\section{Nomenclature}

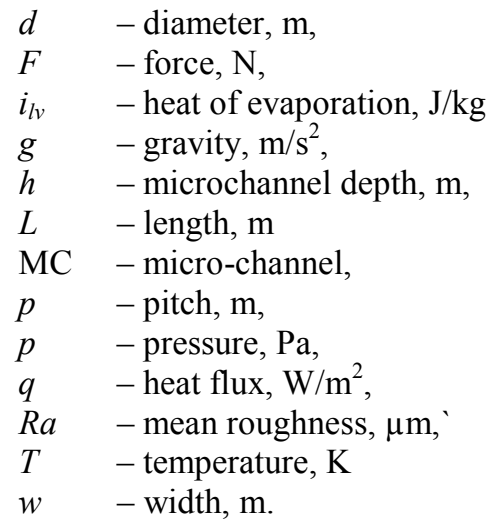

\section{Greek symbols}

$\Theta \quad-$ contact angle, ${ }^{\circ}$,

$\lambda-$ thermal conductivity, $\mathrm{W} /(\mathrm{m} \cdot \mathrm{K})$,

$\rho \quad-$ density $\mathrm{kg} / \mathrm{m}^{3}$,

$\sigma \quad-$ surface tension, $\mathrm{N} / \mathrm{m}$,

\section{Subscripts}

b - bouble,

bt - bottom surface of microfin,

bu - buoyancy

c - contact

cap - capillary,

$l$ - liquid,

s - surface tension,

sat - saturation,

$t \quad-$ top surface of microfin,

$v \quad-$ vapor.

\section{References}

1. M. Piasecka, Heat Tran. Eng. 35 (10), 903-912 (2014)

2. B. Maciejewska, M. Piasecka, Heat Mass Trans. 53, 1211-1224 (2017)

3. B. Maciejewska, M. Piasecka, Int. J. Heat Mass Tran. 107, 925-933 (2017)

4. R. Pastuszko, R. Kaniowski, EPJ Web of Conferences 25, 02019 (2012)

5. R. Pastuszko, EPJ Web of Conferences 45, 01020 (2013)

6. R. Kaniowski, R. Pastuszko, EPJ Web of Conferences 143, 02050 (2017)

7. C. Ramaswamy, Y. Joshi, W. Nakayama, W. B. Johnson, Int. J. Heat Mass Transfer 43, 4257-4269 (2003)

8. R. Pastuszko, Int. J. Therm. Sci. 125, 197-209 (2018)

9. D. Cooke, S. G. Kandlikar, Int. J. Heat Mass Transfer 55 (2012)

10. A. Walunj, A. Sathyabhama, App. Therm. Eng. 128, 672-683 (2018)

11. R. Kaniowski, R. Pastuszko, L. Nowakowski, EPJ Web of Conferences 143, 02049 (2017). 